DOCUMENTOS

\title{
Las ldeas Dominantes en el Convictorio de San Carlos y las Reflexiones de Don José Rezabal y Ugarte, en 1788 , sobre el Plan de Estudios Reformador del Claustro.
}

Por Alejandro Hernández Fobledo.

La azarosa existencia del Convictorio de San Carlos de Lima, y toda la larga via crucis aque soportó, es, en principio, el resultado fácilmente explicable de las sucesivas $\vee$ entre sí contrarias tendencias ideológicas que le fueron impresas por las autoridades docentes encargadas de su gobierno.

Fundado el Convictorio el 7 de julio de 1770 , (1) recibe al nacer, la irrenunciable heredad ideológica de aquellos tiempos: el escolasticismo imperzate y poderoso, punto de partida de su curisoa historia.

Al primer rector, canonigo José Laso de Mogrovejo -espíritu moderadamente abiērtoge Pelesfuvollieservadarda, inicial actitud disonante con las oficiales pautas directrices dadas para "el mejor gobierno del Real y Mayor Convictorio de San Carlos".

Con un evidente sentido de justicia social por cierto no frecusnte en esa época, yá Laso de Mogrovejo se permitió expresar su sentir profundamente humano respecio al caso concreto de la cpción de grados: "Es un dolor - decía - ver que por lo regular solo se animan a docto rarse los hijos de los ricos, aunque sean ineptos, ó los frailes que bajan de la Sierra de obtener prelacías; $y$ por el contrario, que los es-

(1) 'El expresado Convicterio se fundó en esta Capital de Lima el año 1770, en el local del Noviciado de la Compañia de Jezús, después de la Supresión de los Padres jesuitas por el Exn:o. Virrey Don Manuel de Amat, con arreglo a la Real Códula de 9. Julio de 1769..." "MARGESI DEL NNTIGUO CONVICTORIO DE SAN CARLOS", pág. 23. Libro manuscrito NP 688, Est. "Y" del Ârchivo Central "Domingo Angulo". 
ludiosos hábiles $y$ aprovechados no logren este honor por lalla de dos mil pesos y desmayen en aplicación" (2).

Si tenemos en cuenta el ambiente de entonces, esta actitud del primer Rector, representa sin que acaso él jamás lo hubiese querido, ura positivo avance hacia lo que podría llamarse liberalismo de la época.

Mas aquella etapa promisora fué a la postre infecunda por breve; el rector Laso, exactarnente a los 14 meses de su gobierno, hacía en tresa dei clíso cútgo a su suvesor el Dr. José Arquelladia, dejando como únicas huellas de su paso por San Carlos las truncadas ansias noveiosas que él posiblemente alentó, y en todo caso, el resultado da la pesada labor organizadora de insospechable honestidad.

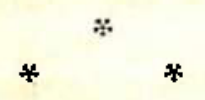

El i? de abril de 1772 el flamante rector Arquellada, en acto do prescrita solemnidad, juraba en el Convictorio "observar y cumplir en su régitien y gobierno conforme a las Constituciones que se le admi. nistraron" (3).

Su propia actividad a todas luces rutinaria, circunscrita según parese a la sola observancia de las Constituciones del Plantel y demás órdenes of:ciales, toda ella presenta al Dr. Arquellada como a un hom. bre mediocre y de notoria incapacidad para el cargo. "Rector inepto" -según la expresión do Leguía- (4). Arquellada es en el fondo un consərvador impertérrito. Conlra su espíritu senil cualquier ensayo innovador estaba condenado a estrellarso irremisiblemente, y en sus manos iban a dormir el sueño eteno clasin más (saludables" sugerencias de sus más entusiastas y mejores colaboradores (5).

(2) Fragmento de una carta do Laso de Mogrovejo al Dr. José Perfecto de Salas, citado gor F. Schwab. BOLETIN BIBLIOGRAFICO DE LA UNIVERSIDAD DE SAN MARCOS. correspondiente a Diciembre de 1944, págs. 150-151.

(3) "RECIRILAIENTO" del sañor doctor don José Árąuellada en el Convictorio de San Carlos. Ob. Cít. fág. 155 .

(4) Jorge Guillermp Lequía: "El PRECURSOR". Lima, 1929; pág. 17.

(5) En el maciso informe de Rodriguez de Mendoza al Visílador D. José Pardo y Riva. doneira, fechado al 23 de marzo de 1816 , réiriéndose a sus antiguos deseos reno. vadores. Y más concrelamente a la sustitución de la cáledra del Maestro de las Senlencias por cira de Historia Eslesíística, intimamente acongojado dice el Rector: "Cuarenla $\mathrm{Y}$ un aiios hacen que siendo yo Maesiro de esie Colegio promoví ante el Superior Gobiemo la conversión de esta Cátedra, en una de Historia Eclesiásiaco. El Rector, mi antecesor, miró con indiferencia esta útil variación, $Y$ sepultó en olvido semejante proyecto..." "LA VISITA DEL COLEGIO DE SAN CARLOS, POR 
Esas son las tendencias ideológicas contradictorias de la primera redad del Convictorio y tales sus primeros representantes. Continuadores arrogantes habrán de sobrevenir después; y en esa sucesión veremos cómo, alternativamente, algunos de ellos superaron a sus respeclivos antecesores en ambas ideologías, no sólo por la más definida posición adoptada dentro de ellas, cuanto sí por el contenido y la estructura doctrinaria dados a las mismas. Así por ejemplo, Toribio Rodríguez de Mendoza, siguiendo y sobrepasando el interrumpido camino de L.aso de Mogrovejo, se propone y consigue la temeraria reforma de San Carlos (6), y a lo largo de los 30 años que dura su victorioso Rectorado, el Convictcrio y las nuevas ideas cultivadas con amoroso tesón en sus aulas, vivieron los días más floridos de toda su existencia (7).

La obra formidable de Rodríguez de Mendoza, con ser fulgurante, se eclipsa a raiz del total y definitivo apartamiento del Maestro, que deviene retroceso y aún amenaza de muerte para el claustro carolino, Y contra aquella irreíragable decadencia en marcha, nada podrá la labor poco edificante de los sucesores inmediatos, llámense Antonio Arenas, Carlos ó Manue: José Pedemonte, Juan Manuel Nocheto ó Matías Pastor.

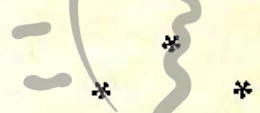

El 28 de octubre de 1842, fué nombrado Recior del Convictorio el Dr. Bartolomé Herrera. Su potente y reaccionario espíritu, su patriotismo tan fervoroso que patede tanático, cen finfsulambición suprema por el bien público, hicieron de Herreralleh paladín del gobierno fuerte, el denodado e irredu:kble scatenedor del orincipio de autoricad, el creador de las teorías de la soberanía de la inteligencia y del gobierno de los más capaces.

DON MANUEL PARDO (1815-1817), pág. 225; publicada por Raúl Porras Barrenechea en REVISTA HISTORICA. temo XVII.

(6) “... Bajo su gcbierno, (el da Taboada y Lemus) el cenónigo don Toribio Rodtíguez da Mendoza consiguió todas las reformas que havía introducido en los esludios do San Carlos..." DON JOSE EAQUiJANO Y CARRILLO por José de la Riva Agüe. ro. (Boletín del Museo Bolivariano. No 12, pág. 466).

(7) "... La época más brillante y floreciente, ha sido la de mi Rectorado... mis discípulos fueron los primeros que llenándose de gloriz desempeñaron cabalmente en sus fúbilicas actuaciones el esxero de este Superior Gobierno, y los deseos del Soberano..." Oficio de 7 de agosto de 1816 dirigido por Rodríguez de Mendoza al Virrey Pezugla. LA VISITA DEL COLEGIO DE SAN CARLOS... Ob. Cii. pág. 244). 
Quien como Herrera tuvo la gallardía de pintar con mano firme el cuadro desolador de le anarquía que sulrió e! Ferú en la iniciación de su época republicana; quien come śl, excaroino formado bajo la infuencia de las corrientes liberales introducidas por Rodriguez de Mendoza, quiten como él que jamás trepidó, ni nunca lo tuvo a menos su cambio ideológico total, ¡qué no haría en su vigilante empeño reformador, convertijo yá en dueño de las aulas de San Carlos!......

"Gran cerebro engastado en un gran corazón", como lo llama Jorge Guillermo Leguía, Herrera tuvo esa rara altivez que parece delito inveterado en nuestro medio, de llamar siempre a las cosas por su exacto nombre. Sin eufemismos complacientes, antes bien, con valentía admirable, proclamó su clericalismo poimista y sil ideal rotundamente conservador.

En su constante afán edificador emprande la reforma radical del Convictorio, dāedo en ella aiención preferente a los estudios de Fiiosolia y de Derecho. A la escuela filosófica sensualista de Locke y Condillac en la que él se formó y a la misma gue posiziormenie condenaría por nociva (8), sustituyó con la escueia ecléctisa de Cousin, primero, y con la escoléstica después. "... Voy a enseñar yo mismo un curso de esta última ciencia, (se referia a la filosolia) aprovechándome de la abunciancia de luz que han vertido sobre eila Escocia, y Fráncia"...", dijo esientóreamente Herrera en su memorable discurso del 20 de enero de 1843 en la solemne cersmonia de apertura del Convictorio. $Y$ en lo que respeftaca tos fotudios-jurídicos, Herrera, en Derecho Natural, reemplazó ol texto do Heinecció por el de Ahrens; el curso de Derecho Internacional fue totalmente tronsiormado al igual que el Canónigo; en Derecho Constitucional inircdujo la doctrina de la soberanía de la inteligencia, en contraposición a la teoría roussoniana de la soberanía popular. En suma, tomando Herrera como leña de su acción educativa: restaurar la Religićn, la Veracidad y la Subordinación -"principios seivaderes de la sociedad hollados de continuo por las revueltas" del caudilismo anterior (9;- el ilusire ultramontano, muy

(8) ..."Esa desgracincia filosctía (se refería a la del siglo XVIII) que llevata en gérmen -el materialismo que se desarclló después, hizo vecila las ciencias más bien fundadas, quiso desiruir el origen coleste cle las ideas sublimes..." ORACION FUNEPRE PRONINCIADA FOK EL DR. BNRTOLOME HERRERA EN LAS EXEQUIASS DEL ILTMO. A.ZOEISPO FR. FRANCISCO SALES DE ARRIETA (1843).

(9) 'La Religión, garanía única de la probidad de los hombres, la veracidad, la su. bordinación, principios salvadores de la sociedad, y hollados de conínuo por las revueltas se inspirarán a la alumnce como lo desea el Gobierno..." (Discurso del 
a su manera, devuslve al Convictorio su prestigio de otros días; y con la fe de un convencido nó vacila el gran ortodojo en prometer en 1843 , al Vice-Presidente del Consejo de Estado General Francisco Vidal y aI Minisiro de Gobiemo de entonces don Benito Lazo, que "antes de ocho años, una generación nueva saldrá de San Carlos a cegar la fuente de las lágrimas que han nublado con irecuencia la República..." (10).

Así fué en efecto. Obra en la cual Herrera puso su espíritu de patriota y su corazón de maestro, ella dió los frutos esperados. Raúl Porras en un ensayo tan sugestivo como suyo sobre D. José Antonio. Barrenechea, dice textualmente en torno a este particular: "Ninguna ge neración, seguramente, salió de San Carlos con convicciones más firmes y claras, y con ideas más definidas sobre las grandes cuestionest politicas del país y sobre los conflictos del derecho de gentes que la educada por Herrera" (11).

$$
* 0^{*} *
$$

Con el advenimiento de la figura patricia de José G. Gálvez Eqúsquiza al rectorado en 1855 resurgen con brio y lozanía las ideas libernles en el Convictorio. Gálvez, al igual que su hermano mayor don Pedro, fué excarolino, y ambos discípulos de Herrera. El 'año 1852 reemplazó a su citado hermano en la Dirección del Colegio de Guadalupe que llegó a convertirse en el más notable foco del proselitismo liberal.

bajo la égida sobresalientemente democrática del Dr. José Gálvez. E., las ideas cultivadas y profesadas en Guadalupe hallaron en San Carlos campo probidig gana csintápida ynfructífena expansión. Al cuerpo docente integrado por el elemento de la más calificada notabilidad de esos días, le tocó la labor de desterrar la orientación enraizada de Herrera, efectuando una reforma tal, que posteriores cambios operados en el Convictorio no del todo lograron hacerla desaparecer.

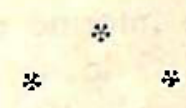

Como se ve, no pudo haber sido más sinuosa la curva del desenvimiento de las ideas en este alto centro de estudios, ni más accidenta-

Dr. Bartolemś Iferrera, Rector del Convicteric de San Carlos, en la ceremonia de aperlura del Plantel, celentada el 20 de enero de 1843. "EL PERUANO" de 21 de Enero de 1843).

(10) Discursc del Dr. Battclomś Herrara... Cb. Cit.

(11) BOLETIN EIBLICGRAFICO DE LA UNIVERIDAD DE SAN MARCOS. Vol, IIK $\mathrm{N}^{\mathrm{C}}$ 3; Marze de 1928, Fä́g. 86. 
da tampoco la vida centenaria del Convictorio Carolino. No habría pues, exageración al afirmar que quizá ninguna institución de su género ha sufrido en el Perú semejante destino.

En ese extraño decurso de zozobrante inquietud, con razón se estima como hecho de mayor repercusión y de más profunda trascendencia cultural en el virreinato peruano, aquella reforma de los estudios, árdua por radical, introducida en las aulas de San Carlos por Rodríguez de Mendoza.

El Plan de Estudios que él formuló con la valiosa colaboración del ilustre presbítero arequipeño don Mariano Rivero y Araníbar, es en la historia de nuestra educación, el acontecimiento de auténtico contenido revolucionario. Como tal fué calificado y tenido por un considerable sector de la nacionalidad; y estando a la declaración de Rodríguez de Mendoza, la transformación que él se proponía realizar, despertó una resistencia tenaz de parte de todo el elemento conservador.

El nombrado Plan de Estudios, previo el minucioso examen que de él hizo don José de Rezabal y Ugarte, fué interinamente aprobado por el virrey Teodoro de Croix (12), y enviado después al Rey de España. Rezabal y Ugarte fué un distinquido personaje que desempeñó cargos importantes en el Perú virreinal. Como Allcalde del Crimen de la Real Audiencia de Lima, formó un compendio alfabético de más de dos mil Reales Ordenes dadas para el gobierno de América después de la recopilación de las Leyes de Indias como juez privativo de Lanzas y Medias-Anatas, publicó en 1792 un volumen político-legal sobre

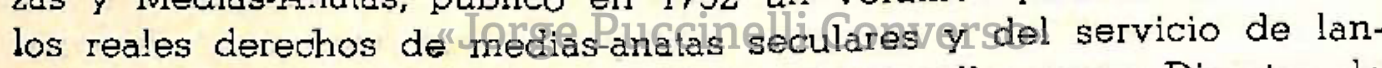
zas a que estaban obligados los títulos de Castilla; como Director de Estudios de la Universidad de San Marcos, nombrado por el virrey Croix "para remediar el contínuo decaimiento de ella", emitió una serie de informes y aprobaciones (13). Nombrado Protector del Convictorio Carolino, formuló el erudito informe que con el título de Reflexiones dirigió al Virrey, fechado el 15 de febrero de 1788 y que hoy publicamos. El citado documento, pese a su notable importancia, ha permanecido sin embargo totalmente ignorado. Mendiburu si bien muy de pasada refiere su existencia, con su característica honradez, no dice haberlo visto. Debemos a la labor tesonera de nuestro notable eurista Padre Vargas Ugarte (14), la noticia de hallarse dicho documento, manuscrito y ori-

(12) LA VIEITA DEL COLEGIO DE SAN CARLOS... Ob. Cit. pág. 215.

(13) Ver OI LIBHO YIV DE CI.AISSTROS DE LA UINIVERSIDAD DE SAN MARCOS. (AA. chivo Sentrai "Domingo AnJuio"?.

(14) Rabén Vargas Ugarte: MANUSCRITOS PERUANOS EN LAS BIBLIOTECAS DE AMERICA. Tomo IV de la Biblioteca Peruana, pág. 66. 
ginal, en 17 fojas, integrando parte de la Colección "Fondo Antiguo" del Archivo de Santiago de Chile, de donde hemos obtenido una copia certificsda, gracias a la benevolencia y cumplida atención del Director de aquel Archivo, don Ricardo Donoso.

El referido informe exhaustivo, ofrece del Plan reformador del Convictorio, algunos aspecios desconocidos y hace más luz sobre otros notoriamente desfigurados. Su escrupuloso estudio puede aportar revisiones necesarias sobre determinadas afirmaciones que el consenso las ha admitido. Tal ocurre por sjemplo con la imputación desmedida respecto. a la posición religiosa del Precursor. Quizá ella se debe mayormente a la crítica, por cierto muy acre, que contra el sistema de los estudios de la Teolozía formuló Rodríguez de Mendoza y su colaborador Rivero y Araníbar, en el Plan de Estudios que ellos hicieron. Mas, semejante crítica era por lo demás perfectamente explicable y iustamente admisible, dado el abuso de da Teclogía escolástica, quie estando a la categórica declaración del mismo Rezabal y Ugarte "ha traído lamentables conseọuencias a la Yglesia".

Sin embargo es de ver la notable preocupación de Rodríguez de Mendoza, por robustecer los estudios teológicos a base de nuevos métodos, para así atajar "el Tesfrío de ellos, muy antiguo en América".

Con evangélica palabra en cuya sinceridad no hay razón para dudar, denuncia el abandono de los conocimientos de la Santa Religión no sólo en las escuelas ide primeras lefras, tsinocaún por parte de los mismos padres de familia. Tal descuido, toda aquella "negligencia más dolorosa me obligaron imperiosamente - lo declara él mismo- a esiablecer desde el principio de mi Rectorado su estudio en todos los días festivos clel año con trecuencias regladas de modo que en los diez, y más años que se detienen en el Colegio los jóvenes adquieran un curso completo del estudio que tanto nos conviene..." (15). Luego refiere su infatiglable propósito por inclinar el mayor número de jóvenes al servicio de la Iglesia; y en ese intrépido afán "nó he omitido - dice ni aún el trabajo de tener a mi cargo Aula de Teología de Jóvemes esco gidos..." (16).

Católico sincero, Rcdríguez de Mendoza mantuvo su credo, limpio de toda apostasía hasta los postreros días de su ancianidad achacosa. Víctima él, de una larga y tenaz enfermedad "cuyos estragos han sido principalmente en la cabeza tanto que a duras penas he podido fijar

(15) LA VISITA DEL COLEGIO DE SAN CARLOS... Ob. Cit. pág. 220.

(16) LA VISITA DEl COLEGIO DE SAN CARLOS... Ob. Cit. ṕ́g. 221. 
mis ojos sobr el breviario", -según propia confesión-, Rodriguez de Mendoza fué hasta su muerte un creyente de verdad. No obstante, es para Riva Agüero "presbítero sospechoso en materia de fe, filósolo sensualista"... y uno de los "escandalosos causantes del menosprecio de la relígión" (17). Estando el veredicto que emana de la documentación dada a la luz últimamente, nos parece exagerada en este caso, la respetable aseveración del notable poligrafo peruano.

Lima, diciembra de 1950.

\section{REFLEXIONES DE DON JOSEPH REZAPAL Y UGARTE SOBRE DIVERSOS PUNTOS DEL PLAN DE ESTUDIOS DEL COLEGYO DE SAN CARLOS DE LIMA.- 1788.}

Exm ${ }^{\circ}$ Sor.

He reconocido con el mibsiorio detenido examen el huevoSplan de estudios que han formado de orn. de V.E. los DrD. don TeribioRedtíguez de Mendoza y Dn. Mariano Ribero, Rector y Vice Rector del Colgo de Sn. Carlos: y aun que el empeño, en qe. V.E. me ha consituido es no solo arduo y Supr. a mis deviles conocimtos. sino aun poco compasibla con las alenciones do $\mathrm{mi}$ pral, destino y de las varias $y$ laboriosas comisiones, que se hallan puestas a mi cargo, no pudiendo menos de obedecer gustoso los superiores preceplos qo. V.E. se digne dispensarme propondré con la Ingenuidad qe. corresponde a mi Ministerio algunas breves reflexiones sobre los diversos puntos, ge. abraza el Plan, para qe. el Consejo raga de ellas el merito, qe. tuviese por oportuno.

Desde luego no puedo menos de expresar a V.E. qe. es digno del mayor elogio el intatigable zelo, qe. manifiestan los autores del Plan por el adelantamio. de las letras y por lacilitar sus mas rapidos progresos a los Alumnos de el Colegio Carolino qə. es sin duda el mas numeroso $y$ floreciente que tiene esle Reyno, $y$ donde toma su Instrucción la parte mas considerable de su ilustre juventud.

No debe sin embargo esperarse, qe. este Plan reuna todas las paries, qe. Constituyen el vasto edificio de la educación nacional.- Las escasas rentas de este Co. leg. prescriben limiles mas estrechos, persuadiendo la necesidad de anteponer los co-

(17) José de la Riva Agüero: "LA NACIONAlizaCION DEL CLERO", "El Comercio", edictón de la mañana del 3 de setiembre de $194 l^{\circ}$, pág. 3. 
nocimiertos a les ga. son inencs esenciales, o de un puro lujo literario. Asi solo se puede aspirar nor ahora, a ce. se formen los cimientos para la ilustracion de la juvenlud en aquellos esmcios. cie. son relativos a lars carreras qe. ofrece este Reyno, y tienen premics y resompeniss, que, exilen la aplicación y sirvan de aliciente, para no desmayar en el as;ero $y$ fraģoso camino de las ciencias.

La thaologia $y$ Jurisprudencia son sin disputa las Profesiones, qe. gozan más poculiamento esta prarrogativa al paso, que son las mas precisas para llenar dignamen. te Jos minislorios Dustorales. y los respectivos al foro.

El methodo. çue so propone en el Plan para instruir a los Jovenes en ambas facultades. está estendido con soídez y combinación; y las nociones, con que los prepara no deben reputarse de un mero ornato, sino conexas $y$ estrechamente enlazadas con el objeto principal, a que se dirigen.

Para rive puecia fomarse un juicio mas exacto de el Plan, expondré mi dictamen, siguiendo puntuaimle. el ora. de las materias que comprehende, y haciendo al mismo liempo algunas ligeris observacicnes qua. servitán de esclarecer los puntos que necesiten de mayor ilustración. o de rectificar los qe. proponen para la reforma de los esludios, sin que me conduzca otro espítiu, que el del zelo do la causa pública, y el de la prosperidad de el Colegio. for cuyo lustre y esplendor debo mirar con aquel paternal dosvelo. cue es justo mo inspire la circunstancia de haberseme confíado pr. V.E. su proteccion.

Empieazan los A.A. de el Plan, proponiendo las ventajas qe. resultaran a la Juvenfud de formar su enseñanza por compendios, y no por obras demasiado voluminosas sobre cuyo punto hacen reflexiones bastantes sólidas y juiciosas. Auncue los críticos no eslan acordes sobre utilinad $y$ algunos bien respetables los miran como frutos do la ignorancia y la desidia, qe. reinaron en la decadencia de el Ymperio, es sin embargo constante, ge. ellos no han conservado el preciosol suco (sic) y fragmentos de algunas obras recomendables] de laeantiguedad dei que no tuvieramos ligera idea, si el genio tulelar de las ciencias no la hubiera sabvado en esta tabla de el naufragio, que sobrevino a toda la literatura en aquellos siglos tenebrosos de la ínnorancia. Por otra parte no debe disputarse, que. los compendios son muy porporcionados para la instruccion de la Juventud, siempre que esten hechos por manos habiles, y presenten los principios elementales de las ciencias con orden y presicion, evitando siempre el esco1lo. que temió Horacio en los que afectaban una brevedad inoportuna.

Como los compendios no se siñen a las rigidas leyes de los analisis y extractos, deben corprchender, no solo la substancia de las ciencias a qe. respeclan, sino tratar sus principios con una amplitud $y$ extencion respectiva; bien sea resumiendo todas las nociones principales contenidas en una obra maqistral $\circ$ bien entresacando de varias Jo mas selecto $y$ exquisito, para formar un cuerpo de instituciones, en que poniendo por base la concision y la claridad se expongan los elementos de cada facultad, que basten para su cabal instruccion: procurando huir la aridez y sequedad, qe. suelen reconocerse en algunos de ellos, en que el conato, que pusieron los Autores de hacerlos breves y sucintos los llegó a reducir a un miserable esqueleto, qe. solo sirve para en. gendrar fastidio y confusion, con no poco peligro de que pasando los Jovenes subcesiyamente de unos conocimientos mal digeridos a otros de diversa naturaleza, contrahigan una superficialidad, que les sea caracteristica en sus respectivas profesiones. 
Este riesjo es digno de precaverse pr. ce. produce lüs mas iatales consecuencias en la carrera literaria, bien gue siempre es preciso distirguir equelies estudios ge. son meramente preparatorios y auxiltares, de les gue consituyen la ciencia principal, a que se dedican los jorenes, fues no dere ser en unos $y$ otrcs igual, ni uniforme su instruccion.

\section{FILOSOFIA}

La definición que hacen los A.5. de el Pian de la fiosophia, comprehende lodos los vastos objetcs de esta ciencio, gue for diferentes operaciones conduce al hombre a inouerir la verdad, elevandole pr. la investigacicn roi de las cosas sensibles, como de las abstráztas a el conocimiento de el Supremo Aulor de la naturaleza, en cuanto alcanza el entendimto. sin los auxilios de la revelación.

El desec de ser feliz produxo en el hombte el anhelo do instruirse, y no satistho. con limitar sus ra:iocinios zokre los objetos ge. se presentaban a su vista. los cxtondio a los qe. necesitaban un examen mus profundo y complicado: y por esto insensible medio se remontc a indagr las causss, y consecutivmte. al principio de lodos los seres, en cuio conocimiento colocó toda su telicidjd, rindiendio el homenaje, que debía a su Criador.

Aunque se pintan con tan vivos coloridos las dernss nicblas, que ofuscaron la luz a estas regiones Americanes, hasla el āno de 1767 en que logró substraerse de el tiranico imperio de la Finlesofia Ziristetehra, ne centemplo justo contibuir a esle gran Philosoto toda la cuipa de la so;historia y frivclided, ge. se introdujeron en las escuelas, siendo mas probable, cee. Esias se nes comunicaron pr. los comenlarios Arubes y principalmenle por Avertces que gustó con predileccion de las subtilezas vanos y pue riles, las que tueron tomanto subresivamente incrementos, hasta el extremo de formar

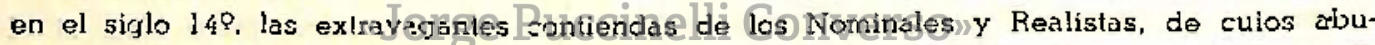
sos se lamenló. entre otros sabios Españoles, el célebre Melchor Cano on el capo. 7. Lib. 9. de Lecis Treolegieis.

Aderitśs es constante que les intérpretes de el estagirita (qe. en sentir de Quintiliano fuá uno de los hombres mas ertinentes de la onliguedud) por su innata obscutidad o falta de inteligencia de sus obras le imputaron varias opiniones contrarias a las ge. el mismo dexj́ estakleciclas, como lo comprotó el Italiano Paze, heciendo un prolixo cutejo con el texto misme, serun observa en Rmi. Truyillo en su Plan de estudios.

Al pase ac. es incontroversihle la glcra de los Philosolos modernos en haber reducido a mejot orden y sistema las zonocimientos de la naturaleza, descendiendo desda las verdados crimitives a les ecmpuestas, hta. ponerlas en el grado de demostracion de ae. son subsccptitles; es iquámte. clerto cue, a pesar de el espiritu geonnétrico, do que se suponen poseidos, han quedado muchas verdades en la misma incertidumbre $y$ obscuridad, con que las vieron los Anliquos, sin que se advlerla otra variacion, qe. la accidental de haberse mudado los terminos escolasticos en otros mas cultos y pompo sos. pero ge. al fin. manifiestan con la ultima evidencia la dabilidad de nuestros estuersos para coniprohender los arcanos y maravillas de lo naturaleza.

Con solo reconocer que la opinion liene en estos tiempos el mismo predominio, que gozó en la antiguedad y ge. no es menor el númera de seclas o partidos, en que están divididos los Philoscfes modencs, sin ponerse jamas acordes en un sistema fixo. 
$\gamma$ antes variàndolos subcesivamente con la mayor veleidad e inconstancla, se verá que Deus tradidit mundum disputationi corand y qe. es preciso confesar que han sido muy lentos les progresos de el espiritu humrno en la Ynquisicion de la verdad. por mas ¿e. algunos ingcnios audazes se hayan vanagloriado de haver corrido el velo ga. la tonia oculta a nuestra inteligencia y comprehencion.

¿Pero ae. concepio deberemos hacer de el orgullo con q. se abrrog̣an algunos Philosofos rodernos el f́astuoso nombre de creadores de nuevos sistemes. sí la maior parte de sus invenlos y opiniones se encuentran er los escritos de los Antiguos. a quienes intentan condenar a un perpetuo blvido? (Esta verdad la ha pretendido com. probir despues de un Anonimo Ynjles que escribió sobre el mismo asuntol el sabio Dutems en la obrs. rue exaba de publicar, sobre el origen de los descubrimientos atribuidos a los modernos, de que habla con el maior elogio el Autor de los tres síglos de la lileratura Iraniesa, exponiendo, que en esta importante discusion se hallan apo. yadas todas les aserciones en pruebas las mas incosteables, $y$ que se citan los pasajes originales qe. las califican.

No se crea por eso que mi designio es desaprobar el estudio de la Philosofia, quo denominamos moderne, ni menos proscribirlo de la escuela.

Reconozco los admirables progresos qe. se han hecho principalmie. en la Prisica y en la Astronomia, y solo deseo que no se dejen alucinar los jovenes con la arrogancia presuntuosa de algunos A.A. que se reputan nuevos Colones de la verdad inspirando aversion a la leclura de los antiguas, a quienes ni debemos mirar con la veneracion supersticiosa, qe. so les ha rendido en otros tiempos, ni dexarles de tributar el reconocimiento qe. se les debe de justicia. pr. ser las fuentes donde hemcs bebido nuestros primeros conocimienlos.

Prefiriendo sabiamente el Plan a los A.A. que profesan Philosolia ecléctica, que usta adic1a a sistema algune antiguo ni moderno. $y$ antes bien, no vinculado su opi. nion en la de ningun Gole. hi teniendo su autoridad pr. Antalible escoge libremente de todo lo mas puro ascendrado $\$$ verdadero. Ise concilian todos los inconvenientes que so seguirán de adherirse ciegamle. a un Philosofo sistemálicoi debiendo ser solo exepclon de esla regla el gran Neuton, en quanto a su fisica, por eslar universalmto. re cibidos los luminosos y proiundos principios de esle sabio interprete de la naturaleza.

Despues de hacer los A.A. de el Plan una critica justa de el Cartier (quo fú adoplado pa. el estudio de la Philosofia en ei inelhodo de estudios qe. dió la Junta do Tempors. al Colegio, despues de la espulsion de los Regulares de la Compañla) proponen para la enseñanza de la Lógica a Heinecio; bien que en la primera adverlencia, reconocen al mírito Supr, de la ge. escribio modernamte. con admirable concision $Y$ claridad Juon Auguslo Ernesto, $Y$ se han impreso en 1785, de orn. del Rey $Y$ la prefieren no solamente para la Logica, sino para Phstchologla, Ontologia o tratado del ente $y$ Theolojia natural ge. compreitenden sus instifuciones filosoficas.

La circunstancia cle estar adornada esta edicion. a impulsos de el ilusirado zelo de el Exmo. Sor. Conde de Floridablanca, con la Historia de la Philosofla bellamsnto escrita por Dn. Manuel Jaaquin Condado, Profesor de el dro. natural en el Seminario de Nobles, hace a esta obra sumamle. apreciable. asi por reunir la ventaja de hacerse el estudio de la Logica y Metafísica por solo un Autor, como poderse incluir en menos tpo. de el que habia prefinido antecedentemente el plan: de el que no debe perderse do vista el bien moditado pensamiento de instruir al mismo tpo a los Jovenes en los principios de la Religion por el Orn. que eslablecen, respecto a ser laman- 
table el descuido que se padece en la educacion pública y privada en un punto tan importante y esencial, contra cu:o invelerado abuso declamó vehementemente el Abad Fleuri en la docta y Filosófica prefacion de su Cartecismo Historico.

Yo verdaderamente he tenido la mayor complacencia, en que se haya substituido a Ernesto para el estudio de la Logica, asi por la aceptacion, con que se corre esta obra (señalada pa. la enser̃anza en los Ssminarios de Ynglaterra segun nos informa el editor Español en el prölogo) como ps. que no estarndo bien prefinidos los limites entre la Logica y ios diverses ramos gue constituyen la Methaphisica, siempre contemplo suma. mente oportuno qe. ambas se aprehendan por un Autor mismo, no solo para que se asegure la debida conexion de unos principios, que tienen tan mutuo enlaze $y$ afinidad, sino por que advierten los A.A. de el Plan) se haria obscuro y dificil este estudio por Autores distintos, por las frecuentes remisiones, que suelen hacer a otros tratados, que no han merecido colocarse en la clase de elementales.

Por otra parte la Logica de Heinecio, aunque sea dichna de aprecio por la purezz de su latinidad y las noticias literarias que contiene, la Jusgo $\sin$ embargo acrehedora a la severa censura qe. hizo de esta obra En. Andres Piquer en la erudita introduccion qe. puso a su Logica y en el dictamen qe. dió scbre un Plan de estudios de Medicina, qe. se hallare incorporado entre las obras posthumas que publicó recientemente su hijo el Sor. Dn. Juan Chrisostomo Piquer.

Como segun el computo qe. hacen los A.A. de el Plan, se pueden concluir la Metafisica y Logica de Ernssto en $8 \circ 9$ meses, en los $3 \circ 4$, que restan para completar el año, podrán exercitarse los colegiales en algunas questiones de escuela; $Y$ aun prepararse à dar un exzmen gral. de ambos tratados, para que se les fixen mas seguramente sus principios.

Para la Phisica se prefiere a Muschrenboek, y son ciertamente bien nerbiosas y fundadas lors razones qe. se alegan pa. adoptarle, no debiendo reputarse de autoridad poco digna de atencion el lee. se hallec señalado para los RS. estudios de Madrid, y los de la Universidad de Alcalá.

Como estudio previo a la Phisica se propone el de los elementos de Mathematicas, contenidos en el primer Tomo de el compendio de Dn. Benito Balls, cuia obra merece justamente la preferencia, no solo por el aplauso gral. con qe. ha sido recibida de la Nacion sino por estar escrita en castellano, en cuio patrio idioma debe aprehenderse esta ciencia por las ventajas, que recomiendan los A.A. del Plan.

La utilidad de la Mathematica, asi para le perioccicn de las artes y las ciencias, como principalmente por los auxilios, que somunica a la Phisica, es tan universalmte. conocida qe. fuera ocioso esforzar esta verdad con los testimonios mas respetables.

Aun para los Jovenes tiene la inestimable calidad de acostumbralos al espiritu de cálculo y combinacion, que es tan necesario para varics usos de la vida, habituandolos al misno ilempo a unir y alcanzar sus ideas que es una de las aptitudes mas esenclales, que deben adquirir, pr. extenderse a todos los destinos y empleos que pueden ocuparse en el comercio civil de las gentes.

Aunque deseara fue el estudio de la Philosofia moral se hiciere pr. los ethicos y Politicos de Aristoteles. por ser (a pesar de la critica de Muratori en sus Refleciones sobre el buen gusto) una do las obras mas perfectas de la antiguedad y estar prescripta fára la enseñanza en las Universidades de Salamanca y Alcálá, son no obstante convenientes los fundamentos, que indican los A.A. del Plan, para preferir la de Heinecio: bien que siempre contemplamos, que una ciencia que se dirige a instruir il 
hombra en el exercizin de toda: sus operaciones segun los dictamenes de la recta razon, deberia aprenderse en idioma bulgar para ge. hiciesen mas comunes y perceptibler unas rocienss y preseptos qe. hatilan cor todos los estados y condiciones.

Este fuś el designio de Piçuer, pero su traizdo de Philosofia moral, sobre ser muy prolixo. mezcla sobrada erudiccion. para que pueda llenar el objeto que se propuso.

La esperiencia acredita, que el que no está bien versado en la latinidad, hace siempre dobiles progresos en las ciencias.

Como esta es lá lenqua sabia en qe. han convenido comunicarse las Naciones cultas la mayor parte de sus conocimientos, debe mirarse su perfecta inteligencia, como instrumentos casi necesarics para su adquisicicn; aun prescindiendo de ser esto el único medio, para en:riquecer nuestras ideas con la lectura de las obras existentes qe. nos ha dejado la Antiguedad en todos los ramos de literatura.

En nirgun Reync habrá en esta parte una mision mas culpable que en este, ya por la insuficiencia de los Maestros qe. abren Aulas, ya por la ansia imprudente, con que anhelan los Padres, a que sus hijos avanzen en los estudios sin advertir, que estos adelantamtos. Son aparentes y superficiales, como que no estan fundados sobre la solida base de la instruccion en el Ydioma latino; cuio defecto les es despues irreparable, haciendolos mirar ccn tedio los Libros elementales de las ciencias y conduciendolos a veces la dificultad de conmprehenderlos a un despecho $\mathrm{y}$ abandono, que pueden producir las mas lastimosas consecuencias.

Esta consideracion dictó a los A.A. de el Plan el arbitrio de poner una Aula de latinidad, er que los estudiantes, que aspirasen a entrar en el Colegio debiesen permanecer un año enters empleando los seis meses primeros en la vercion de los oficios de Ciceron, y en hacer composiciones, segun los preceptos y reglas de Ro!lin, y los otros seis meses en traducir la Piethaficica y Logica de Ernesto.

Yo conceptuo qe. suruesto que deben haker estudiado Gramatica y dar su examen respectivo, sin variār de obieto. sería mas conveniente, que esta Aula fuese de Rethorica, en que se estudiasengalgunas sencillas leglas de este arte tan necesario para fixar el buen gusto y hallar con pureza, elegancia y correccion, haciendo aprehender so lo a los Discipulos a aquellas voces thecnicas de las figuras mas usuales, sin pretender enseñarles toda la vasta terminologia, con que se han recargado esta ciencia pr. cuio meciio solo se ha conseguido el hacerla mas confuza, ccupando la memoria con una nomenclatura, no menos util que embarazosa.

Como el designio de ostablecer esta enseñanza se dirige principalmte. a facilitar a los colegiales la inteligencia de la lengua latina, no podemos adoptar el pensamto. de Pedro Simon Abril, que deseaba se diesen los preceptos de este arte en el idioma castellano, en cuio caso hubiéramos preferido el bello tratado qe. escribió Dn. Anto Campomani con el titulo de Filosofia de la elocuencia, en qe. segun advierte se empezo en su Biblioteca Española, substituye a las reglas esteriles y minuciosas, con que suele fatigar la memoria de los Jovenes, exemplos analizados, que puedan exercitar fructuosamte. su juicio, enseñandoles por este sensillo medio a evitar los desordenes a qe. suele precipitarse la imaginacion sin esta guia.

Siendo indispensable el elegir algun Autor latino me parece deben señalarse las particiones oratorias de Vosio de la Impresion de Madrid de 1781 en que su editor el erudito Sor. Cerda, conducido de el deseo de promover las glorias de nuestra literatura ha añadido tres Apendices, en los que no solo trata de los Griegos y Latinos, que sobresalieron en eloquencia, sino de los Españoles qe. han cultivado este arte y escrito 
con mayor pureza y propiedad, asi el idioma latino como el Palio, cuias noticias nos deben ser por todos respolas interesantes.

Quando no se adoplase el compendio de Vosio, ningun libro me parece mas aproposito qe. los fundamentos de el estilo de fleinecio, que es sin disputa uno de sus mas exelenles tralados, por brillar en el una critica fina $y$ un juicio no menos exaclo que delicado.

Como el tpo. que so designa ns. estos exerciçios es baslante dilatado, podrán darse algunos elementes de icetica que son siempre muy conducentes para perfeccio. nar el gusto; $y$ aun zaria de desear gue torratan los colegiales algunos rudimtos. de la Lengua Griega, siro fueran de un embarazo insupgrable la circunslancia do ser muy ratos en este Reyro los Libros escrilos en este ydioma. y la suma dificultad do zeducir a practica los conocimientos ae. adquiriesen por falta de Eibliotecas y de otros auxilios que son mas faciles en Europa.

No es incompatible cen este pensumiento el ge. se exercite a los colegiales en los ultimos meses en traducir a Érresto pr. gue. siento su latin lerso y florido, servirá no solo para soltarlos en la inteligancia de esle idiomi, sino pira qe. entren después de estudiar la Methafisica y Lozica con mayor disposicion ja. su inleligencia.

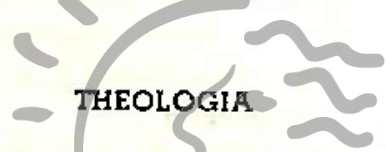

Hacen los A. A. de el Flan unx rehemente invertiva contra la theologia cscolas. tica, la qo. contemple se dirijo principatnente soitira el abuso que en efecto ha traido lamentables consequenias a la Yglasia.

El haverse introducido en la Therioziti en los siglos Nono, Decimo y especialmente en el Undecino las subtilezas $y$ questiones insubstanciales de qo. abundaba la Filosofta Perlpatetica, hizo qe.Desla ciencia Ssgrada separase de el estrecho vinculo, con que estaba ligada con el estudio de la escritura $y$ el de los canones $y$ dogmas de la Ygiesia formandose tres faculàdes dislintas. guando por su intima union y enlace deberian constiluir una sola.

Los caracteres de la verdudera Theoloyia Escolaslica los describen con exactitud Bertit en sus Prolejomeros de su Disciplina Ihoologica Cap?. 30 Denina en el Cap9. 19 de el Lib?. 20 de su Iratacio ie aludio Thanlogui y mejor qe. lodos Melchor Cano

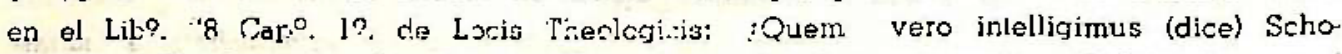
"lasticum Ti:eologum? ¿Aut hey vertem ingue homine ponimus? Opinor inco, qui "de Deo, rebusque divinir, prudenter, doctó é literis instilutis que sacris ratiocinelur : : : "At que obeam causam (continua en el Capo. 20 de el mismo Libro) Scholasti corum dispu"lationibus ixteo sunt heretici infensi. ouod inteligunt, catholicam lidem. quam expug. "nare moliuntur horum sludio, doctrina que muniri. Agnoscunt sane lupi canes, cos"que odio prosequritui et sctı'e. ncaten isis invisum est, que lupos arcet a gregibus "et corum insidias forrs cavet.

Asi me persuado, ale guando combaten los A.A. de el Plan a la Theologia escolastica, seguramente entiende de aquella, que estando fundada en una dialéctica subtil y en uja Metatisica rafinada solo trala las questiones por principios arbitrarios que no tienen apoyo en la escritura ni en la tradición.

En suma condenan los vicios de que adolecen los Scholasticos en las escuelas, pero no en el legitimo uso de esa Theololgia ceniormandose en esla parte con el sen- 
sato dictamen de la Universidad de Salamanca y del $\mathrm{Rm}^{\circ}$ Truxillo en sus planes respeclivos.

Aun antes qe. la obra de Molina hubiera hecho mas jaccionarias las Escuelas ex!lando las ruidesas ccritroversias sobre la gracia y el libre alvedrio, ge. dieron motivo a lus celebres congregaciones de Auxiliss, ya se quejaba amargamte. el sabio Alfonso Castro de los daños que ocasionaba "a la Yglesia el espiritu de partido.

"Ego quidem dice en el Capo. 7 Libo. 19 de su tratado adversus Hereje miserriman "hano dico servitutem, sic ejse humanae sentenciae addictum ut nom licceat ullo modo "illi repugnare quatem patinulur qu, qui se tantum B. Thomae aut scoti, aut ochami "dictis subjicuunt ut als corumplacitis in quos jurase videntur, nomina sortiantur, quidan "Thomistae alij obsequium hominus.

Desecsos los A. A. de el Plan de evitar escolles después de hacer una critica bien fundada de el Cartier $y$ de exponer las dificultades que ofrecen otros Planes para poner en practica los methodos que proponen para el estudio de la Theologia, se deciden abiertamente pr. Duchamel precediendo el estudio de la Historia Sagrada y Eclestastica rr. los compendios ge. indican y los elementos chrenologicos de Berti, en que emplean quatro meses, y los ocho restantes para completar el primer año, en el estudio de los Lugares Theologicos, por el M.S. qe. tiene trabajado el Ror. para el uso de el Colegio, recenociendo no ser la obra de Cano para principiantes, asi por lo que dificulta su inteligencia el elegante lacorismo de su estilo, como por los vastos conocimtos. que supone.

En caso de no haberse formado este M. S. ningun tratado nos parecia mas adecuado for su claridad y conasion que el que cscribió Carlcs Juan Denina con el titulo de Studio Theologie el norma fidei.

Aun que solo he vis!o la obra orande de Theologia que publicó Duhamel, la contemplo justamte. acrehedora a los elcgios ce. la dispensan los A.A. de el Plan, asi for la rureza do su latinidady solidez de su methodo, como principalmente pr. haber hermanado felizmente ja Theolcoia Dogmatiça y Positiva con la Escolastica, y la Mo ral.

No dudo que el compendio formado por el mismo con el titulo: Theologie Clericorum Semenariis accomodate summarium". reunira las ventajas y Excelencias, que se expresan; y mas habiendo sido el Autor uno de los senios mas fecundos y universales que ha producido la Francia, donde le adquirieron una inmorial reputacion, su Astronomia fisica, los tratados de Metheoros y Fosiles su Philosofia vetus et nova y otras obras recomendables, entre las que merece un lugar muy distinguido su edición de la Biblia con notas las mas sabias e instructivas.

Yo no me atreveré sin embargo a resolver, si deberá preferirse para el estudio de la Theologia su cbra grando o el compendio. Aunque está dividida en quatro tumos, comprehendidos en dos volumenes grruesos en $4{ }^{\circ}$. mayor no la contemplo desproporcionada para este designio, y podria concluirse el curso en 4 \%. años sin grave ta. tiga, dando en cada uno un Tomo y su examen respectivo, y en el $5^{\circ}$. un repaso gral. por el compendio, en el que se halla recopilada toda la substancia de la obra principal, y aun tiene demas algunos trátados que añadió Duhamel para completar su curso de Trieologia.

Por este medio en seis ar̃os (conlando el de Locis Theologicis) lograrian adquirir los coleriales unos conocimtos. solidos de esta ciencia Sagrada y este tpo. es igual al qe. se señala en otros Ramos y aun menor ae. el que se designa en el de la Uni- 
versidad de Valencia debiendose tener presente, que la obra de Duharrel corrprelin: de tambien la Theologia. que llama practica. que es el estudio de ! limal dopurada de las escorias, que suelen hallarse en algunas sumas.

Esta circunstancia verdaderamte. la da un realze muy estimable. per que skido en estos Peyses (como juiciosamle. observan los Autores de el Flan) ian necescitios lis ifinisterios cque dependen ce esta siencio es convenienle a la Religion y al Estado. cquc ics Jevenes no tomen sus nociones superficialmente. $y$ for un estudio privado sino que betan sus principios en mananliales puros y limpios para que no se infesten de las opiniones baxas , peligrosas, que exparcieron algunos Casuistas, principalmle. desde el siglo XVI gokernados for principios arbitrarios. y sin poner cuidado an apoyar sus doclrinas en la Iradición, en los SS. PP. o Concilics, pr. lo que han inerecido lá jusla censurà do lus sabios, atreviendose Piquer a decir en el Cap?, 15 de su Logi. ca, que mas parecian libros para Barberias quo para Yglesias: y Mabillon qe. mas prento se podia sacar de los oficios de Ciceron qe. de leer algunas de eslas sumas.

Pưra preferir la obra grande de Duhamel no es razon de congruenzia de pequeño momenlo al hallarse adoptader por el Sor. Cano Obpo. de Segorbe en un melhicto de estudios monasticos: y mas habiendo 3ido aprobado por el Consejo con las expresiones mas honorificas azia este respetable Prelado, ordenado so observaso en las Provincirs de el orn. de la SSma. Trinidad de Casilla. Andalucia y Aragon. segun nos instruye Dn İan Sempere en el tomo $2^{\circ}$. de su Biblioteca Española.

A fin de Fixar en los Colegiales las nociones que vayan adquiriendo, asi, en la Theologia como en las demas facultades covendria ge. al tpo. qe. las esludian hubie sen dos dias « la semana sus respectivas conferencias pr. la noche que traxesen estu diadas algurars cjas de lo atrasado. y gue al Rexte, o Mtro. q. las presidiese los pregun lase a su arbitrio por espacio de media hora, y por otra media continuase la praclíca qe. se observa de defender un colegial por turno la conclusion, que se lo he serialado for el melhodo de escuela, pues poroste medio se acostumbratian a hablar en públi. co, y a reducir sus principios a raciocinios ajuslondos a las Leyes de una buona Lo gica. "Jorge Puccinelli Converso"

El uso de el silogismo en esla clase de exercicios escolaslicos spre. ace. se hace con sobriedad $y$ moderacion, $y$ no con el calor $y$ arrebalo, que inspira el espiritu de partido, es sumamente oportuno, para exponer con mayor vivesa, fuerza y claridad las verdades que se pretenden demostrar. Por otra parle las disputas, que se tienen con ánimo docil $\mathrm{y}$ dirigido unicamente a la averiguación de la verdad, contribuien admira. blemente a flustrarla, y son la piedra de tope en que se descubre la falacia de lor sofismas capciosos, con que se pretende obscurecerla.

"Aunque alounos modernos impugnan los silogismos Heinecio reconoce su ulllidad "et he sunt speciales (habla este sabio crilico de su formación en sus elementos Lo "gicos -par. 1. Cap. 29. prop. 82) guars licet hodie vilipendere soleanl, qui a soll"diore doclrina abhorrent, ulilisimas temen quolidlie experiuntur, quiqụnque veritates "invesligandae studio tenentur ¿Quomodo enim veritalera quis investigavit, ninl racio"clnando? ¿Es guis serecte ratiocinatum persuasus cjse polesl, nis! requlas bonas roli"cinationis perspeclas habeat Solida ergo hace sunt, ullipleraque, que hodio vulgo "displicenle?

De esle mismo sentir son Wollio en varios lugares de su Logica: Dupin en ol malhodo de esludiar Theologia Cap? 25 Mabilion de esludios Monasticos Cap? 10: 
Sain Aubin en su tratado de la opinion Tomo $2^{\circ}$, pág. 6 y otros sabios, que fuera prolixo referir.

Y a la verdad. siendo el raciocinio el exercicio mas noble de potencia mental combinatoria, por cuio medio. segun advierte Piquer en su Logica, descubre, averigua, junta, compone y descompone las cosas entre si segun les corresponde el arte qe. ha dispuesto $y$ enlazado las nociones de manera qe. se presenten subcesivamente con om. $y$ claridad dando reglas exactas para la formacion de los silogismos, lexos de ser acrehedor al insensato desprecio de algunos filósofos modernos, debe reputarse por una de las obras mas sublimes de el entendimiento de los mortales.

\section{DRO. NATURAL Y DE GENTES}

Después de dar los A.A. de el Plan una idea clara y distinta de el dro. natural pasan a convencer la importancia de su estudio con oportunas reflexiones.

Siendo el dro. natural (como decia Ciceron) "non scripsed nata lexiquem non didi"cimus accepimus, legimus, verum ex-natura ipsa arripiumas hausimus, expressimus: ad quam non docti sed factinon institute sed ambustimus, se sigue por necesaria consequencia, que es eterno e inmulable, como ge. contiene las Leyes primitivas, qe. nos dictó el Surmo. Auctor (sic.) de la naturaleza $y$ se hallan gravadas en nuestros co. razones, comuni:andonos un intimo discernimiento de lo justo $y$ lo injusto, ' y de las obligaciones que nes ligan con Dios, con nosotros mismos y con nuestros semejantes.

Como el dro. de gentes no es mas que el mismo dro. natural aplicado a los hombres, $\in$ n quanto viven $\in n$ sociedad, es visible el estrecho enlaze que tienen sus nociones y preceptos.

La conducencia de este estudio es indisputable, principalmente para los qe. se dedican a la Jurisprudencia y asi son justas las provids. ge. solicitan los A.A. de el Plan, en orn. a que no se permita a los colegiales el pasar a las Leyes, sin haber acabado sus curscs de Ghilosofic y Dro. natural, Voms Cogualmente para qe. no se confiera el grado de Bachiller en la Universidad a los colegiales, qe. no acreditasen con certificacion de ei Sec$^{\circ}$. de el colegio, que concluieron las Facultades de Leyes y canones.

Aunque son ciertos algunos de los abusos contra los quales se declama pasajeramente en el Plan pende el remedio de resortes muy complicados en su reforma, como que debe ser comprehensiva de otros puntos no menos esenciales e importantes para establecer en mejor niethodo la enseñanza publica, exije la meditacion mas profunda y combinada.

En el Expedte formado sobre la comision qe. V. E. se digno conferirme de Director Rl. de estudios de esta Universidad de Sn. Marcos, tengo expuesto con la sincer:dad que corresponde a mi Ministerio, el unico medio, que juzgo oportuno, para poner en estado floreciente esta escuela; cuio interesante objeto no pierde de vista el activo zelo de V.E. entre los graves cuidados qe. ocupan insesantemte. sus vastas atenclones.

Contrahiendome ahora; despues de una dipresion gue se ha hecho indispensable a los A.A. que se señalan en el Plan para el estudio de el dro. natural $y$ de gentes, se da la preferencia a Heinecio; y siendo de la edicion de Dn. Joaquin Marin no 
scio ze desvanecen los reparcs que pudieran ocurir para odoptarle. siro quo. nun sa hace nos apreciable esla cbra por las ncias ae. le acompañan.

En su defecto se indica el axelente tratajo de los principios de el cin. esoncial de la naluraleza escrilo por Dn. Anlo. Xevier Pórez lófez, pero aun que lieno ad.nizables maximes $y$ es jigno de eslirtacion nor su meltodo $y$ solidez de principios. no me pa rece apropósito para la enseñanza en el colegio, asi por no estar completo, como por no hriser sido trakaijado sc: su futs: son fse desirgrio.

In caso de no elegirse a Heinecio, ninguno considero, que es mas adocuado a esto efecto gue el Tadeo Werenko, pues sobre ser su obra sumante. ortodoxa y forma. 1a con el tin lo qe. sirviose nara el estudio de el dro. nalural $y$ de genles en las Jriversjdades Calinolicas, liene la ventaja de impugna al mismo lpo. con nervio $y$ nracisión pr. el molncdo de escuela, los sistesmás de los Preluslantes y Liljerlinas; cn uta atencion so podrian escusar las Pfscertarionos qe. debian dictar los Maesiros en los

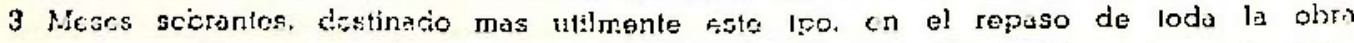
para que ijesen los colegjäles su examen qeneral, que les solidase en sus prin. cifics.

\section{DERECHO CIVII.}

Es muY laudable el zalo que manifieston los A.A. do el plan por tixar el apro cio preferente qe. merece nuestro derecho fatrio, respecto al Romano, que tiane ocupada las primeras atenciones de la escula.

Son varias y sólidas las reflexiones gue hacen para ccmprobar la necesidad de desterar absolulamento la Jurisprudencia Romana, cuio designio, expresurn, scr conformes a los desecs de nuestros Augustos Soberanos dosde los primitivos lpos. de la Monarchia, segun pretenden calilicar recoriendo brevemte. la historia de el orirgen y pro gresos de ntra. legislacion.

Aunque inlentan probat el todio ocn Cue miro la misma Nacion Española las Leyes Romanas desde frincipios del siglo $V$, en que fue invadida por los Vándalos. alanos y Suevos $y$ posteriormte. pr. los Godos, no es Jacil qe. este se convenza pr. los argmlos qe. producen; pues sin embargo de ge, es constante gee. Eurico publicó el primer Códiço de Leyes pocos años desjues do su irrupceion, $₹$ que Leovigildo abrrogó alguras y эñałió otras nuevas, seọun refiere 5n. Ysidoro, es mas probable qe. eslas sirvieron pala todos los Godes y no para los Espuñoles que acostumbrados a) dro. Pomano tardaron mucho tpo. en abandonarle, conservando tenazmte. los usos y costumbres de su antigua dominacion.

La polífi-a dictó a los Godos desde el 1fo. de su conquista la nesesidad de contemporizar con los Pueblos Españoles en un punto tan escncizl, como el do su Govn? cuia alteracion les huviera sido sumemente desagradable, exilando, quizas, formentaciones peligrosas y funestas a una continuacion, cue no eslaba aun solidamente establecida.

Dn. Juan Lucas Cartes er su Themis Hispona, refiriondose a Goldasto en su Tomo 20. Constituttionibus Ymferji, asegula ge. Achatilfo ofreció cn su ediclo a los Espoñoles para tenerles mas gralos. el conservarles el dro. Romano, cuja promesa reyteró dos. pues Athalorico: $y$ al Sor. Mayans en su erudita carta al Sor. Berni, con lo autoridid de Casiodoro y Gregrorio Turonense, prueba que los Godos, leniendo consideracion al 
corlo númelc de su gente dejeron a los pueblos vencidos la eleccion do que se governasen por lcs uscs y costumbres đ̧e. intrcdujeron con la conquista, o por el dro. Romano a que estakan habiluados, cue era siquiendo la opinion mas probable el que se halle recopilato en el Cócigo Theodosiano.

Aun promulgado posteriormente el Breviario. O Código de Alarico (qe. subscribio su Chanziller Aniano y havia compuesio de su om. Goatico o Goyarico de los Cádigos Gregoriano, Hermoger:ano y principalmte. de el Theodociano y de las sentencias de Pau. lo y las Instituciones de (axyo) permanerieren los Españoles en la libre eleccion de su. Govno. manteniendo sitre. las Villos Atimnatas, ileses sus usos y costumbres: siquiendo algunas de las Leyes de los romenos y sugetandose otras a las de sus nuevos conquisladores.

Affrmado el Imperio Godo y siendo muchas las Layes, que hicieron los subscosores de Alarico se compilo al torus sudicum per Sisenardo en el Concilio 4\%. de Toledo segun afirman los A.A. cun que el Sor. Mayans en su erudita carta al Sor. Berni lo alribuya a Chidarsvinto, fretendiendolo comprobèr de las L.L. 5a. et 7a. Tit?. 19. Lib?. 1?. Codicis Visogothorum, de cuio dictanen son igualmente Morales y Dn. Juan tuis Cortes qnes. aseguran ge. es el mismo ge. se nombra liber Judicum en el Concilio de Coyanza, y en olros monumontos respetables de la Historia.

No es de ntro. instilulo el demorarnos en esta discusion, y lo constante es re. Recesvindo (que zeynó primero con su pedre Chindasvinto y despues solo) publicó muchas Leyes de las que componen el fuero juzco; y que la formal coordinacion de estas, distribuiendolas en doze Libtos, a imitacion de el Codigo de Justitniano, se hizo por Egica en el Concilio XVI de Toledo, y que al fin por medio de este nuevo Cócligo, se logró desterrer absolutamente el dro. Romano, habiendose hecho lan famoso qe. aun despues de la perdida de España, guardaron sus Leyes los Mozarabes de Toledo, y luego lué recuperada, bolvio a su enligua observancia, por repelidas confirmaciones de los Monarcas Esoañole

No negamos por eso el constante teson gue han procurado sukcesivamente nuesIros Reyes desde los Godos, estimulando a bs Vasallos, d cue se aplicasen con preferencia a las Leyes petrias, cuio abandono obliggó tambien a Jacobo 19 Rey de Aragon a proscribir en 1264 la Jurisprudencia Romana de su Reyno.

El mismo deseo manilestá el Consejo en la celebre consulta ge. hizo en 1619 in Folipe $3^{\circ}$. la que comenzó sabiamente el Canonigo Dn. Pedro Navarrete con el tílulo de conservacion de Monarquias, quien recopila en el discurso 49 las prohiviciones de nuestra Legislacion, para que ne se citasen las Leyes del dro. Romano.

Es igualmente cierto. qe. ha habido un abuso notable en las Universidades en haver hecho su pral. estudio en las Leyes Romanas, con postergacion de las nuestras, de lo qo. ha resultado ge. consumiendo los Jovenes sus mas floridos años en una Jurisprudencia estranxera (que imrropiamte. se llama Theorica) y trasladandose al foro cen un conocimiento superícial de la práctica se ven constituidos en una region nueva, y sin la aptitud necesaria para desempeñar los ministerios de Juez o Abogado: bien qe. con felizes disposiciones de hacerse en breve tpo. muy capaces de los estilos de los Tribunales, y de formarse eminentes letrados y Ministros como ya lo dexó advertido el Sor. Solórzano en el Libro V. Cap?. 4․ num?. 6\%. de su Política Indiana.

Convengo lambion en "e. el dro. Romano es una compilacion indigesta formada de mas do dos mil libros de los antiguos 9.C., cuios pasages se producen aveces truncados e incomplelos; $y$ que es idea ilusoria la que vulgarmte. se forma quan- 
do se cre que este es un cuerpo systemalico de Leyes qe. esluvo en obscrvancia aun tpo mismo en el occidente.

Lo ge. llamamos dro. Romane es una Coleccion de Leyes, quue mandó hacer el Emperador de el Oriente Justiniano en el siglo VI. a Iriboniano. Teofilo. Dorotheo y otros sabios f.C., de el imperio: y a un la introduccion de la instituta se reconoce dalada en Constantinopla, donde recidian los Emperadores, ge. spre. continuaron en llamarse Romanos, aunoue conservaban pocas Provincias en Ytalia sujelos a su dominacion.

Es sin embargo evidente que en este cuerpo hay muchas Leyes, que estuvieron en vigor en Roma, pero las mas son tomadas de el dro. nalural, de la Legíslacion Egip. cia y Griega, y de las propias constiluciones de Justiniano, que quizo trasladar al Oriente, sin el menor discernimiento las leyes hechas para otros Payses, en que regian Jiversos usos $y$ costumbres.

En conclusion, yo conozco el mal, $y$ apelezco el remedio, fero no puedo conformarme con el qe. adoptan las A.A. de el Plan. ce. se reduce a proscribir desdo luer go absolutmie. el dro. Ricmano de las escuglas.

Las disposiciones de ntra. legislacion no consfiran a su tolal exterminio sino a que se tenga por accesorio o preparalorio ol de niras. Leyes patrias. que son las qe. uni. cante. tienen fuerza exccutriz y nos deben servir de pauta $y$ modelo en el foro. donde solo, pueden alegarse las Romanas. como sontencias de sabios, por carecer de autoridad legislativa respecto a hatlarse promulgadas por Principes Estrangeros.

Aun que se intenta convencer, que el esfirilu de las ropelidas ordenes emanadas de ntros. Manarcas ha sido dirigido a desterrar enteramente la Jurisprudencia Romana de las escuelas, estoy persuadido, a que las interpretaciones, qe. les adoplan los A.A. de el plan son algo violentas $Y$ opueslas a su genuino sentido: pues solo se limilan en ini concepto a dar la justal prelerencia gea se. merece nuestra legislacion, qe. es la que verdaderamenle debe sequirse con la decicion do las causas en todos los Tribunales de la Monarquia Esjañola.

No hay prueba mas aulentica $Y$ perentoria de ssa verdad, que el haber prescrito expresamente el Soberano en los recien!es Planes de Alcalá, Salamanca, Valencia, y en los que se han aprobado para olras iniversidades y colegios, el estudio de el dro. Romano, como previo y prelinuinar alde nlras. Leyes patrias.

Yo concibo, que el Consejo hubiera deseado prohibir de el toda la enseñanza de la Jurisprudencia Romana en las Universiclacieg: pero se ha vísto en la necesidad de atemperarse a el actual estado de ntra. legíslacion mirando este punto con el pulso Y circunspersion qe. exigen la importancia y gravedad de la maleria.

Para poner en planta este designio era preciso qe. se formase antes un nuevo Codigo Español, no solo por 9.C., mas sabios de la Nacion, sino por los Ministros de otros Departamentos, en qe. se contuvieser, con methodo, claridad y preciston las Leyes qe. fuesen utiles y acomodadas a las costumbres de el siglo en que vivimos procurando decidir desde luego las varias dudas promovidas sbre. la intellgencia de algunas Leyes en rue estan divididos los dictamenes de niros. interpretes, prestando margen a que sean contrarias las resoluciones de los Tribunales sobre un mismo punto cuio remedio ya lo contempló necesartio en su tpo. el doctor Senador Cerdan de Tallada en su veriloquio en materia de estado impreso en Valencia en 1,604. 
Todos los cuerpos legales de las Naciones de Europa se halian formados sobre el Dro. Romano y estan consiguientemte. llenos de imperfecciones, como lo demostró convincentemle. Muratori en su tratado de los defectos de la Jurisprudencia.

Yor lo que respecta a ntras. Leyes es tan exesivo el num? de las que se con. tienen en la recopilacion de Castilla, y en los diversos Codigos legales, de que se componen ntra. legislacion, qe. podemos decir con Tácito: Antehac Fiagitils nunos legibus laboramus.

El desorden y confusion que reynan en ellos asi por la mal colocada serie de sus titulos, como por la redundancia, e inconexion de algunas leyes, se hallan justamento ponderados pr. el Pensador; pero quien trató con mas extencion sobre la necesidad de su reforma fué el Dr. Dn. Alonso Maria Azevedo en la idea de un nuevo Codigo, de cuio precioso M.S. nos dá un breve extracto Sempere en el Tomo $2^{\circ}$. de su Biblioteca Española.

Asi Azevedo, como otros sabios zelosos de las glorias de la Nacion, reconocen ser precisa la formacion de un nuevo Codigo legal antes de que se decrete el perpetuo Ostracismo de el dro. Romano en las escuelas.

Aun el mismo Castro qe. declama con tanta energia contra los vicios de el methodo de enseñar la Jurisprudencia viene ai fin a conformarse con este dictamen.

No obstante (dire en el Tomo lo. de sus discursos criticos sobre "las Leyes" pag. "100) para qe. este gerieral destierro de el dro. Cesareo fuere util a la Republica de"biera preceder la formacion de un cuerpo methodico de dro. Español en la forma que "hemos propuesto en la Prefaccion de esta obra. Sin esta tan previa y precisa dis"posicion, privarnos de el estudio de el dro. Romano, poco menos era que de unas, "aunque confusas luces, con que (en algun modo) podemos conducirnos; y quedarnos "quasi en tinieblas: o abandonar un tal qual aun que trabajoso socorro, y quedarnos "poco menos que en una extrema indigencia".

Y en e! Tomo 2? pag. 98 pene entre Bas Clencins, de ge. debe estar adornado el Abogdo. como presisa $\leftrightarrow$ indisfensable a la Jurisprudencia Romana, aunque desea qe. su estudis sea mas breve $y$ metrindico.

Decir quie, asi Castro comc oirns A.A. rałlaren en esta parte por espiritu de condesendencia. os un efugio, que carece de vercsimilidad; pues increpando principalmente aquel con tanta valentía y libertad todos los abusos introducidos en las Univesidades, y en el Foro no es probable qe. dexase de expener sobre este punto su concepto con la misn- imparcialifad, que lo executó en otros de menor trascendencia, ni que contuviese a su pluma el respeto de algunas preocupaciones vulgares, que se hallaban sobradamte. autorizadas.

$\mathrm{Ni}$ debe cręrse que ieniendo en la legislacion española el codigo de las partidas, nos hallamos ya en el caso de abrazar sin timidez este partido; pues aun que sea indispensable qe. esto cuerpo legal es mucho mas exacto methodico y completo qe. el de las Lcyes Romanas (de las que extractó la maior parte de sus desiciones) no puede sin embargo servir de Codigo Nacional, por estar variadas, en el transcurso de mas de cinco siglos, casi en un todo las costurnibres y Govno. de la Nacion, respecto al tpo. en qe. escrtbieron, segun observa el mismo Azevedo en el M.S. ya citado; aun prescindiendo de los defectos que notó en su formacion el Dr. Dn. Franco. Espinoza Abogado de Valladolid, en su tratado M. S. sobre el dro. de Leyes de España, de el que poseo un extracto bastante individual. 
A la verdad el Yugo de esta servidumbra no lo sutre solamente la Nacion Espanola, for que es comun a todas las cjvilizersiones de Europa. El coletre Chanciller Daqueleat en el Mercurial 13a. indica. con su accslumbrada eloquencia las poderosas ra. zones qe. tuvieron las Nacicnes Europeas para adoplat ia jurisprudencia Romana, desde que fueron halladas en Ytalia las Pandectas, expresando, que, como si luvieran cumplidos los destinos de Roma, daba leyes a la pesteridad reinando on loda la Trrar por la razen despues de haver cesado de reinar por lis autoridad.

El descubrimiento de las leyes Romanas ha formado una de las epocas más memo. rables en los fastes de la Historia civit y lileraria cie Eurcpa, $y$ la rapida $y$ universal aceptacion, que consiguieron provino, no solo de reputorse por el mas sublime monumento de la zabiduria de aruellos ciudadanos, $y$ de estas sus desiciones apocadas en los dictamenes ge. insnira la razon natural, sino principslmte. de la conveniencia misma de los principes y las pueblos.

Aquellos hallaron bien cslablecida la idea de la Soborania y solidamte. expuesios los principios de la misor parte de sus reczalies contra las tentativas de los Vasallos y el oroullo y la lierzza de los Magnales.

Estos reconocieron que el espiritu de eslas disposiciones los hacia mas dulces $y$ scciables, y que por su medio podian combatin los dros. lironicos que havio introducido la barbarie y se honraban con el nomkre de boyes en el sistema deudal, oponiendo esta birrera a el poder dinusiro de sus seriores y Barones.

Ási el interes de los Principes y el consentiniento de los Pueblos tuvieron la principal influencia en el alto grado de estimacion a que se elevó la Jurisprudencia Romana sirviendo despues de modelc pora la justicta y equidad oge hillisben en ella, a los demas cuejpos legislativos qe. se publicarcn posteriormente en Europa.

Milita tambien olra razon de congruencia no poco efices para conservar pr. ahora el estudio de el dro. Romano y es que casi todas las Naciones cie Europa lque le son deudoras de los ptimeron tojresos de Cu civilidad) le Sultivan como preliminar al de sus cuerpos legáles norsolo por concepluarlo mun que iniorme $Y$ indefectuoso. como uno de les depositos mis recomendalies do los ilustrados conorimientos de los antiguos P. C. sino por serles muy utiles su instrucción para ponetrar el espiritu mismo de sus propios usos $y$ estatulos que so formaton, o a lo menos se restificaron sobre los principios de la Jurisprudencia Romana.

Por otra parte, siendo estas las huellas que nos dexaron estampadas Martin Aspilcueta, Antonio Águstin, los dos Covarrubias, Menchaca, Larrea, Solorzano y otros varones esclarecidos de la Nacion, que aun hoy a pesar de la superioridad de las luces de esie siglo, los consultamos como oréculos de la jurisprudencia y son las principales antorchas de las resoluciones de los Tribunales, seria empresa no poco aventurarda la do separarnos del camino ga. nos dexaran trillado y pretender subir a la elevada cumbre de la ciencia legal nor sendas incognilas y desusadas.

Estas justas consideraciones me hitn cle!enido para subscribir el diclamen de los A.A. de el Plan; $y$ si el Consfio no estimase convenienle la variacion que solicitan introducir, de emprehender el esludio de la Jurisprudencia Patria, sin tomat algunas nociones de la Romana, podsa adoptar el methodo que juzgare mas oportuno de los que se hallan aprobados para los Universidades de Españá.

Sugetando siempre mi parecer a la censura de tan Augusto y respetable Senado propondré el methodo. que contemplo mas sencillo y proporcionado, para que los cologiales logren instruirse en la Jurisprudencia Romana y Patria. 


\section{DRO. ROMANO}

No siendo justo que los Jovenes empleen el dilatado tpo. que suelen consumir en las Universidades, en el esludio de la Jurisprudencia Romana que solo debe considerarse como preparatorio el do el dro. Español podran pasar el primer año la Historia del dro. Romano, por Carlos Martini u otro Autor y las Instituciones de Justiniano con el comentario de Vinio añadido y correxido pr. Dn. Juan Sala, que no solo suprimió muchas cosas inutiles, sino ilustró varios pasages substituyendo en las notas, en lugar de el dro. de Holanda, el Español; con algunos apendices de materias peculiares a ntra. legislacion.

Por este medio conseguiran los Jovenes tomar desde luego alguna tintura de el dro. Patrio, advirtiendo su discrepancia o conformidad con el Romano, y estudiando en dos meses la Historia de el dro. podran pasar en los diez restantes hta. el titulo de Legatis $y$ en el año siguiente lo que resta de la instituta.

En el tercer ar̃o darán el titulo de Regulis juris, que aun que no llena bien su efecto por estar sumamente diminuto y falto de orn. y conexion contribuie mucho su estudio para facilitar ias resoluciones de los casos ocurrentes; y seria de desear que se formarse un Quado. con una bieve explicacion poniendo estas reglas con mejor methodo y enlaze, y añadiendo las demas, que se hallan esparcidas en el Codigo y Digesto, por cuio medio se conseguiria la ventaja de tener recopilada en un pequeño volumen toda la substancia y espiritu de los principios generales dictados por la Ley Natural.

Bermudez de Pedraza en su arte legal recogió algunas axiomas qe. podran servir de bastante exito para hacer este Quad?. como igualmente el Legum delectus de Domat, aunque no esta formado precisamente con este objeto.

En dos o tres meses se puede concluir este estudio, aunque se añada el de el Tit 9 . de Verborum significatione; y en lo restante del año se dará un repaso general de toda le instituta con el comentario expresado, $y$ su examen correspondiente.

\section{"Jorge Puccinelli Converso»}

\section{DRO. CANONICO}

Como el estudio de la Jurisprudencia Eclesiastica es tan necesario en los Letrados pr. hallarse ligados intimamite. sus principios con la práctica de los negocios forenses y con la defensa de las Regalias mas apreciables de la Corona, contemplo que no es conveniente qe. los Jovenes pasen a instruirse en el dro. Patrio, sin haber tomado antes unas exactas nociones de el Canonico.

Aunque desearan fuesen mas extensas las instituciones de Selvagio, merecen justamte. la preferencia, asi por poder suplirse algunos puntos que se reconocen tratados con sobrada concision pr. lars antiguedades Christianas de el mismo Autor, como por hallarse acomodadas en la edición de Madrid de 1784 a las Leyes, costumbres y disciplina Eclesiastica de España con adiciones sabias y oportunas.

Sin embargo de no haver grave inconveniente en dividir los examenes en la forma que se indica, me parecia methodo mas facil y expedito el de dar en cada uno de ellos un Libro de los tres que contiene la obra.

Por lo que hace al Lib?. 1․ juzgo se podria pasar con los Prolegómenos que preceden en el term ${ }^{\circ}$. de seis meses; en quatro el segundo; $y$ en tres el tercero do 
rodo, que en treze meses se concluleren todas las instilucioncs. y empleando los cinro restantes al año $y$ medio en un repsso gral. $y$ on su exunten resjestivo, udquiririan 'or colegiales una periecta inteligencia de los elementos de este dro.

En lus seis meses que quedan para completar el curso do dos atios, podirian estu diar la suma de concilios de Carranza, o la de Cabajucio, y el compendio do la His. toria Eclesiestica de Eerti traducito por el Frai. teniencio al atims tro. sus contr. rencias $y$ Sebastien del dro. Canonigo por ol methaio de eszuels is ius so deberial pro curar ge. rodasen sobro aquellas moterias cue no estan bion esclarecijas en las Sumas Canonicas, corro son; la independencia del, Sobetania en lo temporal: los caractores de ambas potestades y margenes que tienen prescritas: ${ }^{\prime}$ excrcicio de la protoccion real en los recurzos de fuerza $y$ retencion de bullas; el Patronalo de Castilla y do las Yndias y otros puntos de igual importancix. en que os prociso instruir solidamto. a los Jovenes; para que no se dexen preocupar de las deciamaciones ultrinontanas $Y$ pus. dan zonocer, que los pdincjpios que adoptan estan fundados sobre la irme haso rie la Sagrada Escritura de los Concilios $Y$ de la entiguo disciplina do la Yalesia.

El discurso sobre la Rl. Jurisdiccion, que preceds il tratado do las maximas sobre los recursos de fuerzas do Dr. Joso Covarrubias, y aun todo el cuerpo de la obra y sus apendices, pueden iustrar mucho a los Jovenes sobre cslos delicujos puntos do nuestra disciplina Ecsca. pr. que se hallan on ells exelenlemente dosignados los limites iustos de el Sacerdocio $y$ de el Imperio.

\section{DERECHO A1. DE ESPANA}

Concluidos los dos años de el dro. Canonico podrian pasar los colegiales al estudio de el dro. Rl. para el que zreferimos por ahora las instituciones de los DD. Aso., $\gamma$ Manuel (sin embargo de no ser esta obra completa) potaser la mas methodica $y$ acomodada que tenemos para la enseñanza, $y$ hallarse scñalada, en esta atencion, en el Plan de la Universidad de Valentia. Clinell CONVerSO»

Aun que el compendio del dro. publico y comun de España de Dn. Vizte Vizcayno es digno de la estimacion que distruta, no me parece propio para la instruccion de la escuela; pues sin enibargo de que haya varizdo el orn de los títulos, $y$ dando claridard a algunas Leyes, Spre. se haze tedioso y molesto el estudio de Los Textos. quando no esta recopilado su espiritu en un cuerpo formal do instituciones, que enlaze los principics con una sorie systematica, que facilite su inteligencia, y ayude a que se fixen mas permamentemente en la memoria.

Debe darse previamte, a los Discipulos la introduccion que antecede a las instltuciones, en que se describe historialmte. el origen $y$ progreso de nira. legislacion, 1e. niendo al mismo tpo. presente la Thermis Hispana de el Scr. Dn. Juan Lucas Cortes de la edicion de Dn. Franes. Cerda en que se halla traducida con elegancia al Latin la carta oute escrilsió don Gregorio Mayans al Dr. Berni que es uno de los opúsculos mas bien trabajados de aquel ilustro jurisconsulto.

En un año pueden concluirse comodamte, las instituciones; en cuio tpo. se procura rá que los Discipulos manejen con trecuencia los cuerpos legales, para que les facilite su uso y comprehencion.

Por via de conforencias se pueden estudiar al mismo tpo. las Leyes de Toro con el comperitio do el corsentario de A.nio Gimez ge. dío a luz don Pedro Nolasco Lla- 
no, pues la obra principal je Gcmez. es schradamente proiixa, y se difunde en muchas questiones por mera incidencia o conexión, que aunque escritas con solidez de juicio y magisterio, no son precisas para la inteligencia de aquellas Leyes, ni menos para su ilustracion.

Adquiridos estos conocimientos deberían entrar los colegiales en la Academia de el dro. Español e Yndico si se lograse qe. S.M. aprobase su ereccion, bajo de las reglas establecidas en otras de igual instituto y por este medio, dispensando la clemencia de el Rey, los privilegios, que solicitan los A.A. de el Plan para los Académicos, podriarn cesar los abusos que son consiguientes a la multitud de Abogados, de qe. abunda esta ciudad con menos decoro de el qe. corresponde a esta noble Profesión, experimentándose en ello lo qe. dixo mucho tiempo hace el Obispo Dn. Rodrigo en el Capto. 28 de su espeio de la Vida: Ubi A.dbocatorum turba strepit, ibi litum anfractibus to ta civitas ardet, nec domus aliqua a iitigio vacat.

Para que ei Consejo pueda instruirse con exactitud e individualidad de los fondos y rentas de el Coleqic, su aplicación y numero de Maestros Pasartes y Colegiales, convasdiría que V.E. arcinnañse a este Expediente ccpia del qual promovi en mi ingreso a la Protectoria y traslade inmediatamte. a manos de V.E. con un Estado prolixo y circunstanciado.

No solo contemplo de necesidad indispensable le dotación de 300 ps. que señala el Plan para los Mzestros, sino zue juzgo debiera extenderse mas, si el colegio estuviera en proporsión, de verifical semeiante aumento.

Con este aliciente se conseguiría poner la enseñanza en sugetos de la idoneidad y suficiencia que requieren unos ministerios tan apreciables, y que fuesen mas fixa $y$ estable su residencia on el colegio a efecto de asegurar por este medio su mas solida ingtruccion y el mejor aprovechamto. de los Discipulos.

El merito que se contraxese en los empleos de Rector, Vice-Rector y Maestros, siempre que estos llenasen dignamente por algunos años las obligaciones respectivas a sus destinos, deberia reputarse por muy distinguido $y$ relevante y ser atendido con preferencia en las solicitudes, Gque tuviesen Cen la Carrerar Ecca, o Secular. Esta justa recompensa les serviria de un poderoso estimulo para avivar su esmero y dedicacion a un objeto tan interesante como el de la pública educacion.

Para conseguir este nuevo arreglo, y qe. haya masa suficiente que pueda cubrir las asignaciones de los Mtros. sin perjuicio de las demas atenciones indispensables en el Colegio; se hace preciso poner expedita la cobranza de algunos ramos aplicados por la piedad de el Rey a este destino; y la protección, que dispensa V. E. a este cuerpo literario, le hace consevir lá lisongera esperanza de gẹ. logrará ver prontamte. verificados sus designios, con conocidas ventajas de la Religion y de el Estado.

Siendo la pension de 112 ps. 4 rs. qe. pagan los Colegiales sumante. corta para proveer a su subsistencia en una ciudad donde estan los alimentos tan caros, y cediendo este nuevo methodo de estudios en su beneficio, podría (a lo menos en el interin qe. se hagan efectivas las expresadas aplicaciones) subirse a 140 ps. y este moderado arbitrio serviria para formar parte de el fondo qe. deberá empelarse en el aumento de la dotación de los Maestros: que son precisos para establecer la enseñanza, segun el arreglo prescriplo en este Plan.

Como los puntos que se indican de reforma de la Universidad, tienen conecxion, segun insinuué antecedentemente, con el Expediente, que corre separado ,me abstengo de producir sobre ellos mi dictamen por los motivos que tengo indicados. 
Estas son las obvias imparciales raflexiones. gue me ha diclado mi vivo deseo do el acierto entre las incesantes ccupaciones de mi empleo y las anqustias de cl tpo. en que me he hallado constituido, pr. estar tan proxima ha saida de lin Frugata la Concordir. donde me na significado V. E. nuz degea re dirija el frol. de este Expediente. Sino llevan la ulima lima me cehen servir de diseulpa las circunstancias expresadas y la insuticienciz de mis concoimtos. para desempeñar la confianze que $V$. E. se ha servido dispensarme, debiendio asegurar a V. E. qe. no ha sido defecto de mi zelo el qua esta constantemts. dispuesto a consagrarse con la major activiciad. a quanto sea drs servicio de el Soberano $y$ de el obsequio do V. E..-

Lima y Febro 5 de 1788.

Joseph de Rezabal y Ugarlo.

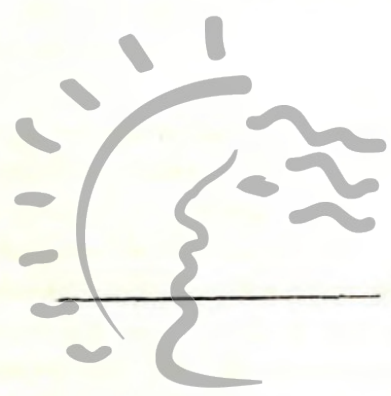

